\title{
MATERIAL INSTRUCIONAL APRESENTANDO CONTEÚDOS DE MÉTODOS COMPUTACIONAIS PARA O ENSINO DE FÍSICA
}

\author{
Michel Emile Marcel Betz \\ Rejane Maria Ribeiro-Teixeira \\ Instituto de Física - UFRGS \\ Porto Alegre - RS
}

\section{Resumo}

É inegável a necessidade do uso de ferramentas computacionais no ensino de Física desde o nível básico. Por isso, é aconselhável que se promova o estudo envolvendo ferramentas e métodos computacionais já na formação de professores de Física, como nos cursos de Licenciatura, pois o fato de os professores não se sentirem confortáveis para incorporar metodologias envolvendo essas ferramentas em sua prática de ensino, muitas vezes, deve-se à falta ou ao desconhecimento de materiais instrucionais que lhes sirvam de motivação e orientação. Neste trabalho, descreve-se um material instrucional desenvolvido na forma de hipertexto, com o objetivo de contribuir para alterar esse quadro. São considerados alguns softwares úteis no ensino da Física, que oferecem recursos interessantes e estão disponiveis para os sistemas operacionais $L i$ nux e Windows. Os principais recursos de cada um dos softwares são apresentados a partir de uma situação-exemplo de Física, que serve como ilustração para demonstrar a sua utilização. O primeiro software apresentado é a planilha eletrônica e, a seguir, é estudado o software Modellus. Ao final da apresentação de cada um

\footnotetext{
Instructional material presenting contents of computational methods for Physics Teaching

* Recebido: fevereiro de 2012.

Aceito: agosto de 2012.
} 
desses softwares é sugerido um exercício como uma tarefa a ser realizada. O material ainda aborda os softwares HotPotatoes e CmapTools. Grande parte do material instrucional aqui apresentado foi utilizada em disciplina de "Métodos Computacionais no Ensino de Física", ministrada no âmbito do Curso de Especialização a Distância "Física para a Educação Básica" destinado ao aprimoramento da formação de professores atuando na rede pública de ensino do Estado do Rio Grande do Sul e oferecido pela UFRGS na integração com o Sistema Universidade Aberta do Brasil.

Palavras-chave: Métodos computacionais no ensino de Física. Softwares educacionais. Material instrucional.

\section{Abstract}

The importance of the use of computational tools in Physics teaching from the early years of school is indisputable. In order to take the most out of the allying of Physics content s with computational tools, the study of available computational softwares and methods should be stressed also in the teacher's formation, already at undergraduate level. The fact that school teachers do not feel at ease with incorporating these technologies into their teaching practice is often due to the lack of instructional materials that could motivate and guide them, or to their unfamiliarity with such resources. In the present work, we describe an instructional material developed in hypertext form, with the goal of contributing to change that picture. We consider a few softwares aimed at assisting and improving Physics teaching, and available for Linux and Windows platforms. The main features of each software are presented starting from a Physics problem or situation, which also stands as an illustration of its possible applications. The first software presented is the "Spreadsheet". Next, we explore the software "Modellus". To close the presentation of each of these softwares, we suggest an exercise as a task for the reader. The material also addresses the softwares "HotPotatoes" and, finally, "CmapTools". Much of the instructional material presented here has been applied in the 


\begin{abstract}
discipline "Métodos Computacionais no Ensino da Física" taught within the non-presential specialization course "Física para a Educação Básica" aimed at improving the training of teachers working in the public school system in the brazilian state of Rio Grande do Sul, and jointly promoted by UFRGS and Universidade Aberta do Brasil.
\end{abstract}

Keywords: Computational methods in Physics teaching. Educational softwares. Instructional materials.

\title{
I. Introdução
}

Aprender Física provoca nos alunos, frequentemente, uma reação desfavoráve $^{[1-3]}$. O rigor necessário nos raciocínios, bem como o cuidado exigido nas observações e medidas são desafios que nem todos eles enfrentam de bom grado. O uso, muitas vezes inevitável, de formalismo matemático pode aborrecer quem não se sente adequadamente preparado ${ }^{[4]}$. Como consequência, para o professor, a tarefa de ensinar Física se torna árdua e, muitas vezes, ingrata. É, portanto, necessário que se busquem formas para tornar o ensino-aprendizagem mais atraente, sobretudo para os alunos da educação básica. Assim, o trabalho do professor poderá vir a ser mais eficiente e gratificante.

Os computadores, disponíveis atualmente em grande parte das escolas e na maioria dos lares, podem contribuir bastante para esse objetivo ${ }^{[5-9]}$. Os jovens usam o computador dedicando horas do seu dia a jogos e à comunicação através de sítios de relacionamento ${ }^{[10]}$, reservando pouco tempo a, ou até mesmo negligenciando, o estudo dos conteúdos das disciplinas da escola. Os autores do presente artigo acreditam que a utilização do computador em sala de aula e nas tarefas de aprendizagem a serem realizadas fora dela pode ajudar bastante a atrair a atenção do aluno e motivá-lo para o estudo.

Entretanto, o principal obstáculo à disseminação do computador como ferramenta de ensino talvez seja o próprio professor, que muitas vezes não possui desembaraço no uso dessa ferramenta ${ }^{[11,12]}$. Com exceção talvez dos recémformados, os professores de Física - e de ciências, em geral - precisam de um complemento de sua formação, com o objetivo de familiarizá-los com as ferramentas e os métodos computacionais que podem auxiliá-los nas suas atividades didáticas.

Cursos presenciais de formação continuada para professores em exercício são oferecidos, mas não atendem aos professores que trabalham em cidades mais 
afastadas dos centros universitários. Outra possibilidade é o oferecimento de cursos na modalidade $\mathrm{EAD}^{1}$, os quais, no entanto, demandam uma dedicação do professor muitas vezes difícil de ser conciliada com sua jornada didática na escola.

Ademais, o fato de os professores não se sentirem confortáveis para incorporar metodologias envolvendo ferramentas computacionais em sua prática docente comumente se deve à falta ou ao desconhecimento de materiais instrucionais que lhes sirvam de motivação e orientação. Ao fazer uso dessas ferramentas, é importante que o professor procure explorá-las em conexão com os conceitos físicos associados através de questionamentos e reflexões.

Existem vários tipos de softwares que podem ser utilizados no ensino. Não se pretende, aqui, fazer uma revisão detalhada dessa ampla área de recursos didáticos. Para situar o leitor, são listadas abaixo algumas categorias que se acredita serem de particular relevância:

- Planilhas eletrônicas ${ }^{[13,14]}$;

- Ambientes integrados de modelagem, simulação e animação ${ }^{[15-17]}$;

- Repositórios de simulações e animações ${ }^{[18-20]}$;

- Análise de vídeos ${ }^{[21]}$,

- Testes digitais ${ }^{[22,23]}$;

- Construção de mapas conceituais ${ }^{[24]}$.

Neste trabalho, apresenta-se um material instrucional digital desenvolvido utilizando alguns desses softwares úteis no ensino da Física, que oferecem recursos interessantes e estão disponíveis para os sistemas operacionais Linux e Windows. Espera-se que ele possa cumprir o papel de orientar o professor e motivá-lo para desenvolver o seu próprio material didático.

\section{Organização do material instrucional digital}

Embora existam muitos softwares que se mostram úteis no ensino da Física, no material divulgado neste trabalho, julgou-se preferível focar o estudo em apenas quatro, escolhidos por serem livres, bastante conhecidos e diversificados na sua finalidade de uso. Especificamente, o material foca a tradicional planilha eletrônica, um software de modelagem e animação, um software de elaboração de

\footnotetext{
${ }^{1}$ Por exemplo, o Curso de Especialização a Distância "Física para a Educação Básica", destinado a professores atuando na rede pública de ensino do Estado do Rio Grande do Sul e oferecido no período 2009-2011 pela UFRGS na integração com o Sistema Universidade Aberta do Brasil. A estrutura desse curso está disponível em:

$<$ http://www.ufrgs.br/sead/cursos/especializacao/2009/curso-a >. Acesso em: 16 jan. 2012.
} 
testes eletrônicos e um software de construção de mapas conceituais (e outros tipos de mapas).

O material instrucional elaborado é organizado em seis capítulos, com dois capítulos dedicados a cada um dos dois primeiros softwares estudados, e um capítulo focando cada um dos demais softwares. Ele é apresentado na forma de hipertexto, detalhando os procedimentos a serem seguidos na utilização de cada software, sempre focando um exemplo de interesse no ensino da Física, introduzido no começo do capítulo.

Na Fig. 1, é apresentada a página inicial do primeiro capítulo, "Planilha eletrônica I". Os links na parte superior da interface estão presentes em todas as páginas do material e permitem navegar de um capítulo para outro. No fim de cada página, links facilitam a volta ao topo da página e a passagem para a próxima página (ou também para a página anterior, quando a página em questão não é a primeira de um capítulo). No menu à esquerda, são mostrados os links para as várias seções do capítulo em questão, iniciando tipicamente por uma introdução e o detalhamento de um conteúdo de Física, que serve de exemplo a partir do qual são introduzidos os vários recursos do software.

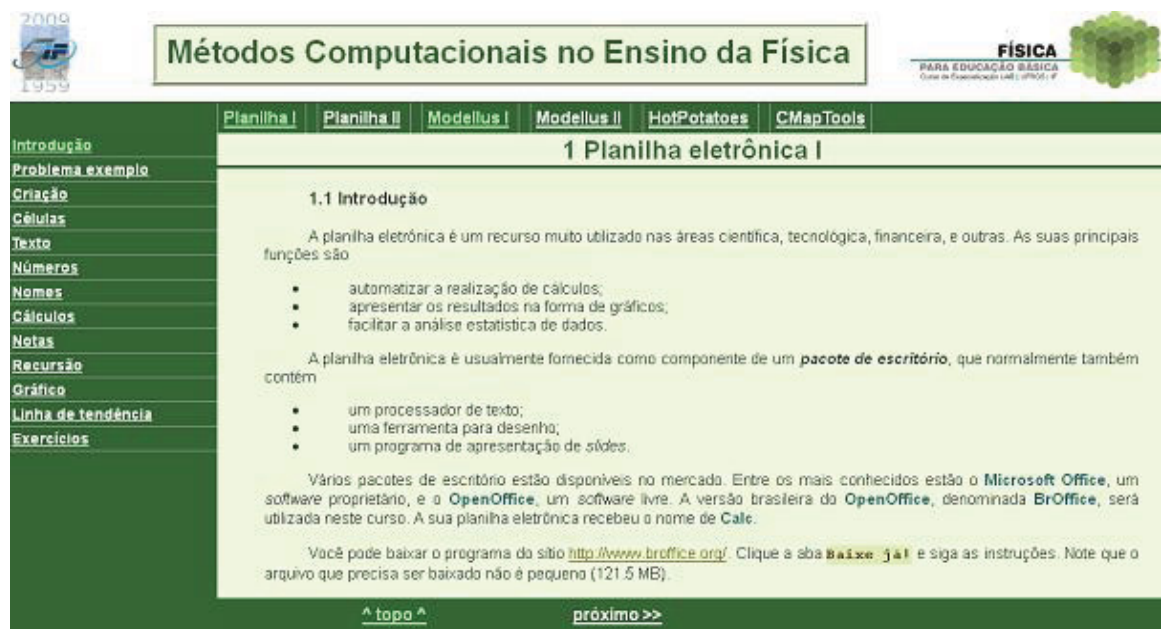

Fig. 1 - A interface do material instrucional; como exemplo, é mostrada a página inicial do capítulo "Planilha eletrônica I".

Como sistemática de estudo, o usuário é convidado a reproduzir passo a passo o exemplo ilustrativo. No fim dos quatro primeiros capítulos, são propostas 
tarefas que incluem algumas extensões e modificações do material ensinado no exemplo. Caso o usuário venha a encontrar alguma dificuldade, ou meramente quiser comparar o resultado do seu trabalho ao "gabarito do professor", ele poderá encontrar no sítio do projeto ${ }^{[25]}$ os "arquivos-fonte" associados aos exemplos e às tarefas.

Como alternativa ao estudo sequencial do hipertexto e para facilitar consultas, é fornecido, também, um mapa de navegação pelo material, destacando as funcionalidades de cada software. Esse mapa, apresentado na Fig. 2, foi elaborado com o aplicativo CmapTools, discutido no sexto capítulo, e serve, também, como ilustração do uso desse recurso.

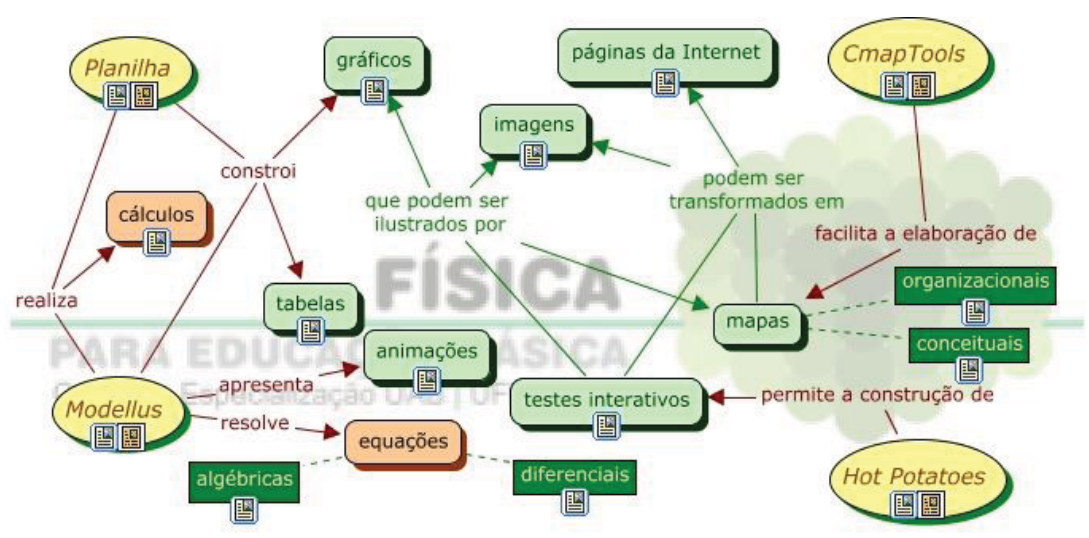

Fig. 2 - O mapa de navegação pelo material, construído com o aplicativo CmapTools.

Embora o material seja concebido para estudo e consulta diretamente na rede Internet, uma versão da totalidade do hipertexto na forma de um único arquivo compactado também está disponível no sítio do projeto. Ao usuário que não puder ou não desejar acessar repetidamente a rede, bastará "baixar" e descompactar esse arquivo para dispor do material instalado no seu computador. Para quem desejar imprimir o material, também está disponível um arquivo contendo todo o texto em um formato adequado para esse fim $(p d f)$. 


\section{A planilha eletrônica}

Dentre os softwares apresentados no material, o primeiro - a planilha eletrônica - é o mais familiar. Provavelmente, um bom número de professores já faz uso desse recurso para tabelar resultados de avaliações, calcular médias, etc. No entanto, talvez muitos deles nem percebam que se trata de uma ferramenta poderosa em tarefas indispensáveis no processo de ensino-aprendizagem da Física, em especial a realização de cálculos e a elaboração de gráficos. Assim, facilitar e automatizar tais tarefas significa propiciar um estudo mais completo e dinâmico de sistemas usualmente abordados pelos métodos tradicionais, bem como permitir a discussão de sistemas até então considerados demasiadamente complexos. Naturalmente, já existem, na literatura, tentativas interessantes nesse sentido: Barbosa, Carvalhaes e Costa ${ }^{[26]}$ descrevem como o professor de Física do Ensino Médio pode se valer de uma planilha eletrônica para discutir o pêndulo simples; Oliveira e Nápoles ${ }^{[27]}$ usam a planilha apresentando um estudo do movimento oscilatório de um sistema massa-mola com um enfoque para o Ensino Superior; Bloch ${ }^{[28]}$ apresenta, na forma de um livro-texto, uma introdução ao uso da planilha eletrônica para engenheiros e cientistas.

Por tratar-se de software livre, disponível para todos os sistemas operacionais, optou-se pela planilha eletrônica $\operatorname{Calc}^{[13,29]}$ do pacote de escritório BrOffice. Já que um dos objetivos propostos é o de convencer o leitor - provavelmente um aluno de licenciatura ou um professor de ensino básico - que, com a planilha, possa expandir o seu horizonte, é desejável que o tema de Física usado como ilustração não seja trivial, podendo ser até um tanto complexo. Considera-se, portanto, a compressão e o aquecimento de um gás ideal, começando naturalmente por uma revisão dos conceitos, das relações e das leis envolvidas.

O material detalha passo a passo os procedimentos a serem seguidos na construção da planilha, desde nomear e salvar o arquivo, passando por referenciar células e então inserir texto, valores numéricos e equações, até gerar uma sucessão de passos recursivos por arraste de um conjunto de células com o mouse. Uma captura de tela da parte essencial da planilha resultante pode ser vista na Fig. 3.

Evidentemente, tabelas de valores numéricos não são, em si, a melhor maneira de prender a atenção dos alunos e comunicar informação, mas a planilha oferece recursos convenientes e poderosos para a apresentação de resultados em gráficos. As últimas seções do primeiro capítulo estão dedicadas a eles. O gráfico elaborado como ilustração pode ser visto na Fig. 4; foi considerado o caso particular da transformação isotérmica de um gás ideal. Nesse caso, o procedimento serve apenas para que o aluno possa verificar a validade da forma funcional ajustada aos 


\begin{tabular}{|c|c|c|c|c|c|c|c|c|}
\hline & A & B & $c$ & D & E & $\mathrm{F}$ & \begin{tabular}{l|l}
$G$ \\
\end{tabular} & $\mathrm{H}$ \\
\hline 1 & & & \multicolumn{6}{|c|}{ Compressão e aquecimento de um gás ideal } \\
\hline 2 & & & & & & & & \\
\hline 3 & \multicolumn{2}{|c|}{ Constantes } & & \multicolumn{2}{|c|}{ Parámetros } & & \multicolumn{2}{|c|}{ Condiçöes iniciais } \\
\hline 4 & \multicolumn{2}{|c|}{$R(\mathrm{~J} / \mathrm{mol} . \mathrm{K})=8,31$} & & \multicolumn{2}{|c|}{$q(\mathrm{cal} / \mathrm{s})=1000$} & & \multicolumn{2}{|c|}{$p($ atm $)=1$} \\
\hline 5 & \multicolumn{2}{|c|}{$1 \mathrm{cal}(\mathrm{J})=4,19$} & & $w(W)=$ & & & \multicolumn{2}{|c|}{$V\left(m^{3}\right)=1$} \\
\hline 6 & \multicolumn{2}{|c|}{$1 \mathrm{~atm}(\mathrm{~Pa})=1,01 \mathrm{E}+05$} & & & & & \multicolumn{2}{|c|}{$T(K)=300$} \\
\hline 7 & & & & $V \rightarrow V$-wat $\rho$ & & & \multicolumn{2}{|c|}{$p(\mathrm{~Pa})=1,01 \mathrm{E}+05$} \\
\hline 8 & & & & & \multirow{2}{*}{\multicolumn{2}{|c|}{$E=3 n R T / 2$}} & \multicolumn{2}{|c|}{$n(\mathrm{~mol})=40.51$} \\
\hline 9 & $p(\mathrm{~Pa})$ & $V\left(m^{2}\right)$ & $T(\mathbf{K})$ & $E(J)$ & & & & \\
\hline 10 & $1,010 \mathrm{E}+5$ & 1,0000 & 300,0 & $1.515 E+5$ & & & \multirow{2}{*}{\multicolumn{2}{|c|}{$n=p \vee /(R T)$}} \\
\hline 11 & $1,055 \mathrm{E}+5$ & 0,9901 & 310,3 & $1,567 E+5$ & \multirow{3}{*}{\multicolumn{2}{|c|}{$\begin{array}{l}E \rightarrow E+(q+w) d r \\
q \text { em joules }\end{array}$}} & & \\
\hline 12 & $1,101 \mathrm{E}+5$ & 0,9806 & 320,6 & $1,619 E+5$ & & & & \\
\hline 13 & $1,146 \mathrm{E}+5$ & 0.9715 & 330,8 & $1.67 \mathrm{~A}+5$ & & & & \\
\hline 14 & $1,193 \mathrm{E}+5$ & 0,9628 & 341,1 & $1,723 \mathrm{E}+5$ & \multirow{2}{*}{\multicolumn{2}{|c|}{$T=2 E(3 n R)$}} & & \\
\hline 15 & $1,239 E+5$ & 0,9544 & 351.4 & $1.775 \mathrm{E}+5$ & & & & \\
\hline 16 & $1,287 E+5$ & 0,9464 & 361,7 & $1,826 \mathrm{E}+5$ & & & & \\
\hline 17 & $1,334 \mathrm{E}+5$ & 0,9386 & 371,9 & $1,878 \mathrm{E}+5$ & & & & \\
\hline 18 & $1,382 E+5$ & 0,9311 & 382,2 & $1,930 \mathrm{E}+5$ & & & & \\
\hline 19 & $1,430 \mathrm{E}+5$ & 0,9239 & 392,5 & $1,982 \mathrm{E}+5$ & & & & \\
\hline 20 & $1.479 E+5$ & 0,9169 & 402,8 & $2,034 \mathrm{E}+5$ & & & & \\
\hline
\end{tabular}

Fig. 3 - A planilha eletrônica relativa à compressão e ao aquecimento de um gás ideal, construída com o aplicativo Calc. Estão visíveis notas explicativas associadas a algumas células, informando o conteúdo de Física relevante.

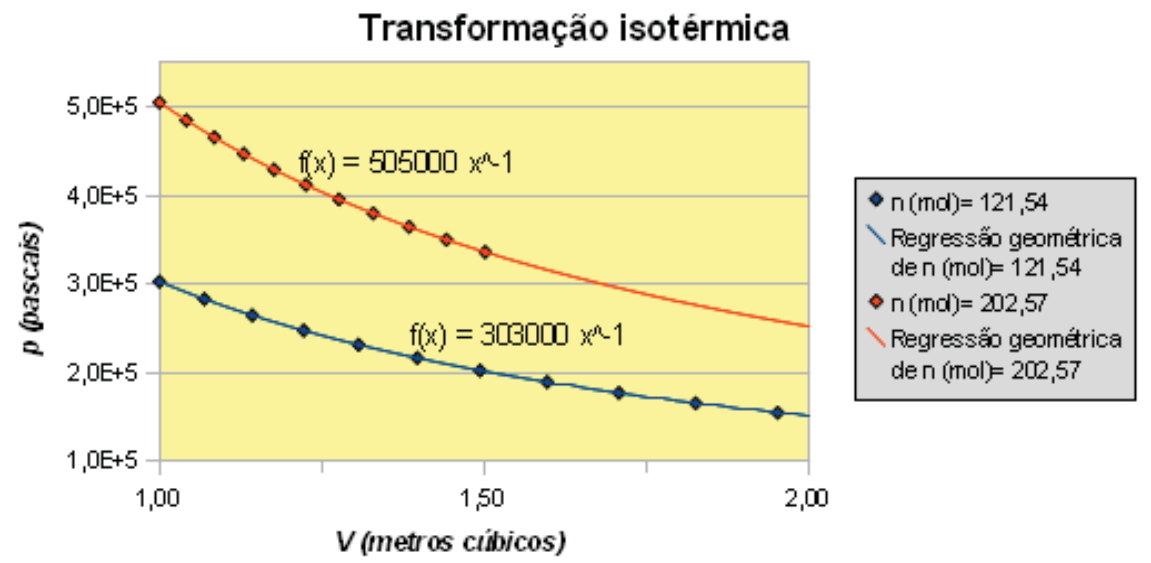

Fig. 4-O gráfico p-V para transformações isotérmicas, construído com a planilha eletrônica com ajuste de uma função analítica indicada ao lado de cada curva, com " $x$ " representando o volume e " $f(x)$ ", a pressão. Os dois casos apresentados diferem pela quantidade de gás. 
dados numéricos, pois a dependência da pressão no volume é simples e bem conhecida. É comum, na modelagem de um sistema qualquer, a função teórica não ser conhecida e a regressão ser, então, um ajuste aproximado aos dados numéricos.

Como exercício, é proposto adaptar a planilha-exemplo e o gráfico associado a outro caso particular conhecido: a transformação adiabática. Para incentivar a investigação, pelo aluno, de outras possíveis aplicações, foi incluído também no material um resumo da teoria do sistema massa-mola, com orientações para a realização de cálculos e construção de gráficos, considerando sistemas sem e com amortecimento.

No segundo capítulo, é demonstrada a utilização da planilha eletrônica na administração de uma disciplina, facilitando, por exemplo, o cálculo de médias e a atribuição de conceitos aos alunos.

Procura-se apresentar e demonstrar a utilização de outros recursos da planilha que não foram trabalhados no capítulo anterior, como "Ferramentas de análise de dados". Para tal, foi escolhido como ilustração analisar os resultados obtidos por uma turma de alunos em uma avaliação parcial de uma disciplina.

O objetivo não é fazer um estudo aprofundado sobre estatística de dados, mas apresentar uma revisão sucinta sobre os conceitos básicos usados em uma análise estatística simplificada. A seguir, os recursos da planilha eletrônica são utilizados para facilitar a análise no âmbito tanto de medidas ditas de posição, como de medidas de dispersão dos dados.

Ao longo dessa análise, são detalhados os passos orientando o usuário para os recursos disponíveis no acervo de funções estatísticas e matemáticas do programa Calc.

A partir de um conjunto de dados - as notas obtidas por alunos em uma prova-exemplo - são estudadas medidas ditas de posição como a média, os valores máximo e mínimo, e as análises do tipo contagem do número de alunos com nota acima ou abaixo da nota média da turma. Quanto a medidas ditas de dispersão dos dados, são estudados a variância e o desvio padrão.

Para verificar como as notas dos alunos estão distribuídas em relação à média da turma, apresenta-se o cálculo do número de alunos com notas iguais ou maiores que a média. Para tal é usada a função CONT.SE, que permite que se analise um conjunto de dados dentro de determinados critérios, estes podendo ser descritos no argumento da função como um número, uma expressão ou um texto.

A Fig. 5 apresenta a captura de tela que mostra parte do conjunto de dados e os resultados obtidos, por exemplo, para a média e o desvio padrão, e, na barra de fórmulas, a função CONT.SE e o resultado obtido com este cálculo. 


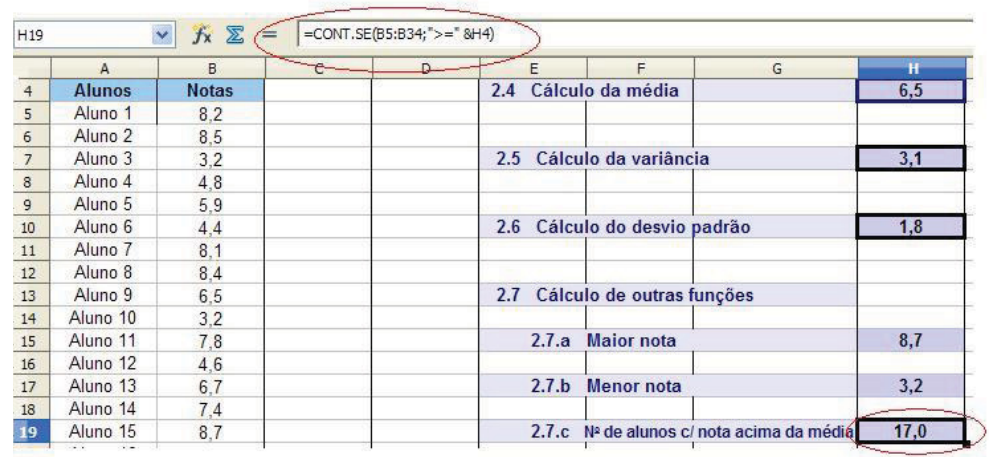

Fig. 5 - Captura de tela que mostra, à esquerda, parte do conjunto de dados e, à direita, os valores calculados e na barra de fórmulas a função que calcula o número de alunos com nota igual ou maior que a média da turma utilizada como exemplo.

Também são apresentados os procedimentos para construir, a partir da definição de intervalos de notas, um gráfico que faça uma associação da frequência com que as notas obtidas pelos alunos se distribuem em cada intervalo. O gráfico construído é de colunas do tipo histograma, com os intervalos de notas e a frequência como estas se distribuem em cada um dos intervalos. Esses dados e o gráfico construído são mostrados na Fig. 6.

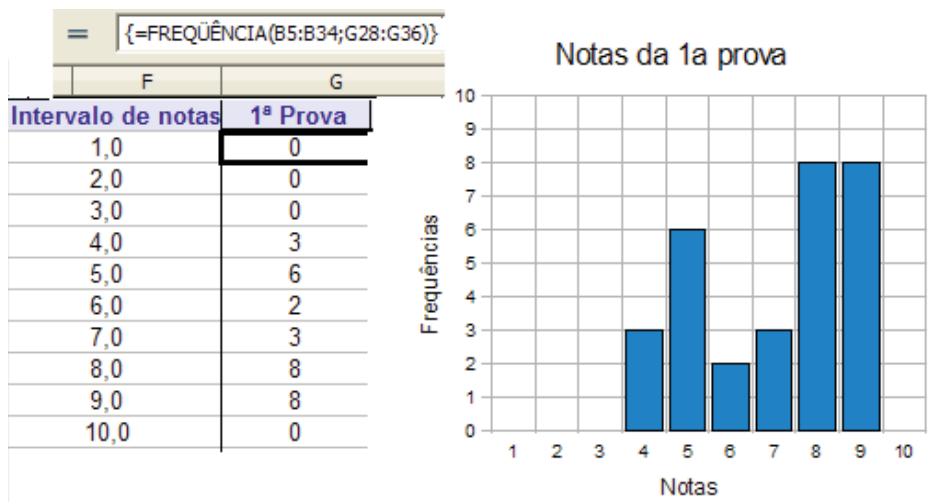

Fig. 6-Captura de tela que mostra, à esquerda, os intervalos de notas e a frequência com que estas se distribuem em cada intervalo e, à direita, o gráfico construído com esses dados. 
Como exercício, sugere-se ao usuário a construção de uma planilha, cujos dados de entrada serão as notas dos alunos da turma-exemplo em três provas de um semestre letivo e a análise dos resultados da turma como um todo e do desempenho de cada um dos alunos. Aqui, a função que permite que se analise um conjunto de dados dentro de determinados critérios poderá ser usada para encontrar o número de aprovados e de reprovados na disciplina-exemplo. A tarefa sugerida permite que se faça uma análise do desempenho da turma como um todo.

\section{O software de modelagem Modellus}

Embora a planilha eletrônica seja sem dúvida uma ferramenta poderosa, pode-se argumentar que ela apenas permite realizar, com maior facilidade e apresentação mais atraente dos resultados, tarefas - cálculos e elaboração de gráficos que podiam tradicionalmente ser efetuadas com uma calculadora de bolso e papel milimetrado. Contudo, a informática moderna oferece recursos adicionais que podem ampliar os procedimentos de ensino-aprendizagem usuais, dentre os quais se destacam as animações.

Existe uma grande variedade de técnicas para a montagem de animações ${ }^{[30,31]}$, mas, para fim de elaboração de material didático, é desejável que uma animação possa ser construída com relativa facilidade, e integrada naturalmente aos demais aspectos do estudo. Dentre os softwares que oferecem tais potencialidades, o Modellus ${ }^{[15]}$ representa uma excelente escolha. Detalhes sobre a história desse aplicativo e a motivação para o seu desenvolvimento, bem como recomendações para o seu uso didático podem ser encontrados na tese de Teodoro ${ }^{[32]}$. Como exemplos de materiais didáticos baseados no uso de Modellus, o leitor poderá consultar uma introdução à informática para o ensino da Física, preparada por Aguiar $^{[33]}$ e um texto de mecânica, ao nível de Fisica geral universitária, redigido por Veit e Mors ${ }^{[34]}$. Vale mencionar, porém, que esses trabalhos fazem uso de uma versão antiga do aplicativo, Modellus 2.5, desenvolvida para uso com o sistema operacional Windows. O presente material foca uma versão mais recente, Modellus 4.01, programada em Java e, portanto, executável em qualquer sistema operacional. Deve-se notar que existem diferenças bastante significativas entre essas versões, de maneira que programas elaborados com a versão antiga do software infelizmente não serão, em geral, funcionais na versão atual.

O campo de possível aplicação do software Modellus é muito amplo, pois ele faculta a análise de qualquer modelo científico, desde a sua formulação matemática, passando pela apresentação de tabelas e gráficos de resultados, até a criação de animações. Já que se pretendia focar mais especificamente esse último 
aspecto, um tema de mecânica era particularmente indicado como ilustração. Optou-se, portanto, pelo movimento de um projétil, primeiro (no Capítulo 3) sem levar em conta o arraste do ar e, depois (no Capítulo 4), incluindo na modelagem o efeito do arraste.

O estudo do movimento do projétil sem arraste do ar ilustra a modelagem através de equações algébricas e o uso de funções de biblioteca, por exemplo trigonométricas, oferecidas pelo Modellus. A Fig. 7.a mostra a versão final da janela de modelagem do exemplo desenvolvido no material. Além do tempo de voo, do alcance e das componentes da velocidade e da posição, estão calculadas as energias cinética, potencial e total, quantidades utilizadas para demonstrar a construção de um gráfico (Fig. 7.b).

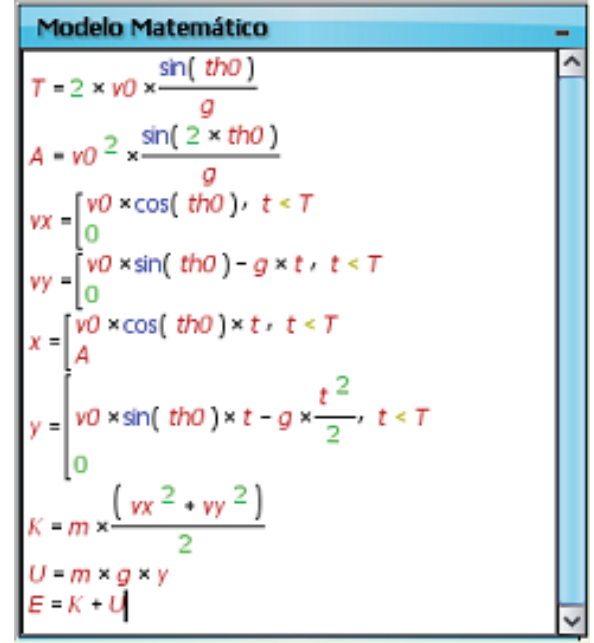

(a)

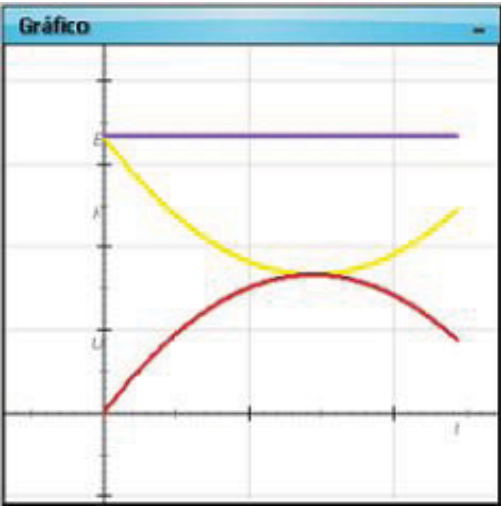

(b)

Fig. 7 - Elementos da modelagem com Modellus do movimento do projétil sem arraste do ar: (a) janela de modelo matemático; (b) gráfico das energias como função do tempo - linha amarela: energia cinética (K); linha vermelha: energia potencial (U); linha roxa: energia total (E).

Embora o Modellus não ofereça recursos de programação muito sofisticados, é importante o usuário perceber que ele, na verdade, executa repetidamente um laço, constituído dos comandos digitados na janela de modelo matemático e controlado pela variável independente (usualmente o tempo nas aplicações em Física). É útil alertar o usuário para a disponibilidade de comandos simples de 
execução condicional. Como se vê na Fig. 7.a, tais recursos foram aproveitados no exemplo apresentado no material para fazer o projétil parar quando ele volta ao nível de lançamento (ou seja, quando $t=T$ no modelo), como aconteceria aproximadamente em um jogo de bocha na areia fofa. A Fig. 8 mostra dois instantâneos na animação de cinco projéteis nessas condições, ilustrando, também, o uso de rastros estroboscópicos e de setas para indicar vetores.

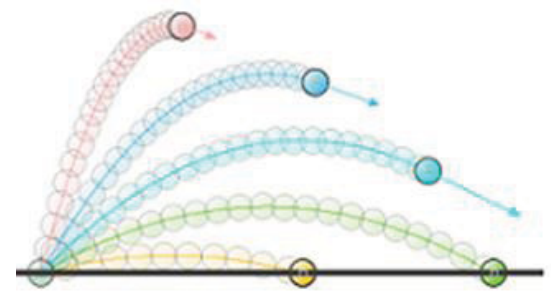

(a)

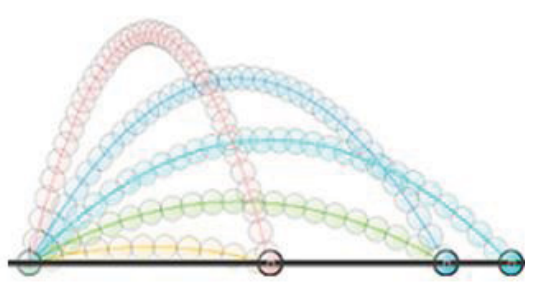

(b)

Fig. 8 - Instantâneos da animação do projétil (sem arraste do ar) construída com Modellus: (a) três projéteis ainda estão em movimento; (b) todos os projéteis já pararam sobre o solo.

Um recurso bastante interessante e poderoso oferecido pelo Modellus é a integração numérica automática de equações diferenciais ordinárias de primeira ordem. Ao usuário com conhecimento de cálculo diferencial, basta digitar a equação, na familiar notação matemática, fornecendo a condição inicial, que o programa se encarrega de calcular (numericamente) a função. Mesmo em um ambiente escolar no qual os alunos não tenham conhecimento de cálculo diferencial e integral, essa potencialidade pode ser explorada pelo professor. Por exemplo, no caso do movimento do projétil, ele pode incorporar na modelagem o efeito do arraste do ar e discutir com os alunos a forma da trajetória, a dependência na massa, a dissipação de energia e outros aspectos. A Fig. 9.a mostra o modelo matemático apresentado no material, que corresponde a arraste linear (força proporcional à velocidade). Na Fig. 9.b, vê-se uma captura de tela da animação, que demonstra ainda a inclusão de imagens que tornam a visualização mais atraente e de cursores que facilitam o ajuste de parâmetros. Como explicado no material, as componentes da velocidade inicial também podem ser definidas de maneira conveniente, arrastando com o mouse, antes de iniciar a animação, a ponta da seta roxa que representa a velocidade. 


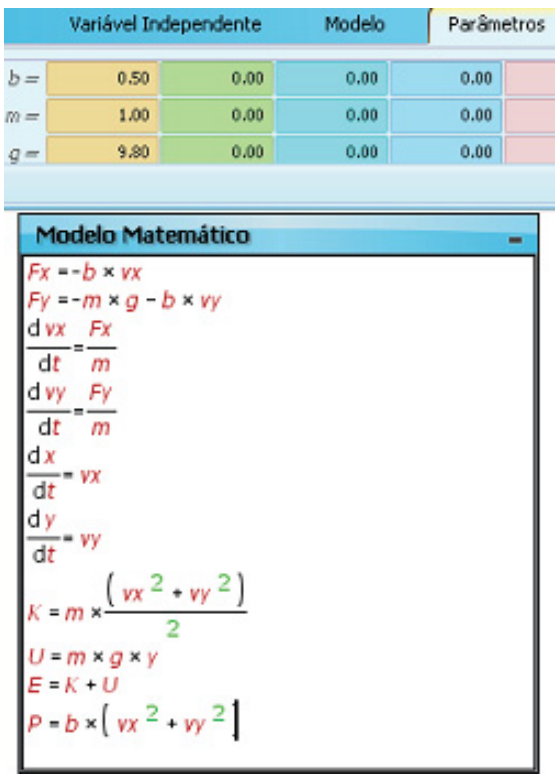

(a)

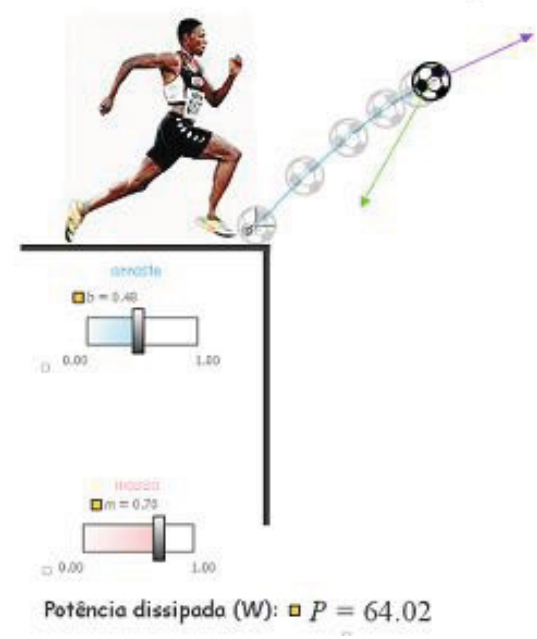

(b)

Fig. 9 - Modelagem com Modellus do movimento do projétil com arraste do ar: (a) modelo matemático com faixa de digitação dos parâmetros; (b) animação com vetor velocidade (roxo), vetor força resultante (verde) e ajuste dos parâmetros, coeficiente de arraste e massa da bola, por cursores, azul e rosa, respectivamente.

Como tarefa para o aluno, sugere-se realizar um estudo semelhante àquele detalhado como exemplo, mas baseado na hipótese de dependência quadrática da força de arraste no módulo da velocidade. O material introduz a fórmula bem conhecida ${ }^{[35]}$ que relaciona a força com a densidade do fluido, a área da seção transversal do projétil e o coeficiente de penetração aerodinâmica do mesmo, estimulando o aluno a utilizar essas quantidades na modelagem.

Embora as ilustrações, no material apresentado aqui, foquem a mecânica e os movimentos, deve-se enfatizar que Modellus pode ser utilizado proveitosamente nas mais variadas áreas da Física e outras ciências exatas. Dorneles, Veit e Moreira ${ }^{[36]}$ descrevem, por exemplo, como se deu a aprendizagem de alunos de uma disciplina de Física básica superior que trabalharam com modelagem computacional e simulações criadas com o Modellus para estudar circuitos elétricos simples. 


\section{Elaboração de testes eletrônicos interativos com HotPotatoes}

No Capítulo 5, é estudado um software destinado a facilitar a elaboração, pelo professor, de testes interativos eletrônicos ${ }^{[37]}$ Especificamente, é apresentado o software HotPotatoes ${ }^{[22]}$, que oferece, entre outros, testes de escolha múltipla, associação de palavras, preenchimento de lacunas em textos e palavras cruzadas.

Da mesma maneira que nos aplicativos anteriores, como ilustração na apresentação do programa HotPotatoes é utilizado um assunto específico de Física - a descrição dos resultados obtidos e dos conceitos envolvidos em um dos experimentos típicos dos primórdios da Física Quântica, o efeito Compton, que evidencia diretamente as propriedades corpusculares da luz em sua interação com a matéria. Embora o exemplo aqui apresentado possua um foco principalmente em conteúdo, deve-se enfatizar que nada obriga a tal escolha; o software apenas constitui uma ferramenta digital que o usuário pode aproveitar, seja qual for a abordagem didática adotada.

Procura-se introduzir passo a passo os recursos do software HotPotatoes, mostrando inclusive as configurações convenientes a serem utilizadas. A partir de um conjunto de testes interativos, o usuário pode criar uma página $W e b$ ligando uma sequência de testes.

São apresentados exemplos de testes interativos criados com as seguintes opções do aplicativo: (i) JQuiz, teste de escolha múltipla, de resposta curta e de seleção múltipla; (ii) JCloze, exercício no qual o aluno deverá preencher lacunas em um texto; (iii) JMatch, exercício de associação de palavras ou frases com outras palavras ou frases. É sugerido ao usuário explorar os outros dois aplicativos JMix, que permite elaborar testes nos quais o aluno deve ordenar palavras ou frases dadas para formar um texto correto, e JCross, que serve para a elaboração de testes na forma de palavras cruzadas.

Na Fig. 10, é apresentada a captura de tela onde está sendo criado um exercício de preencher lacunas do texto com o JCloze. O procedimento é redigir o texto que se deseja e, depois, escolher as palavras que corresponderão às lacunas na versão final do exercício - estas aparecem sublinhadas no texto em preparação como mostrado na figura.

O arquivo $W e b$ de um teste JQuiz de seleção múltipla é apresentado na Fig. 11. Na porção esquerda da figura é mostrado um texto de apoio que foi inserido no próprio exercício usando-se o recurso "Acrescentar texto de apoio". Esse recurso permite evitar que o sucesso na realização do teste seja decorrente apenas da memorização do conteúdo. 


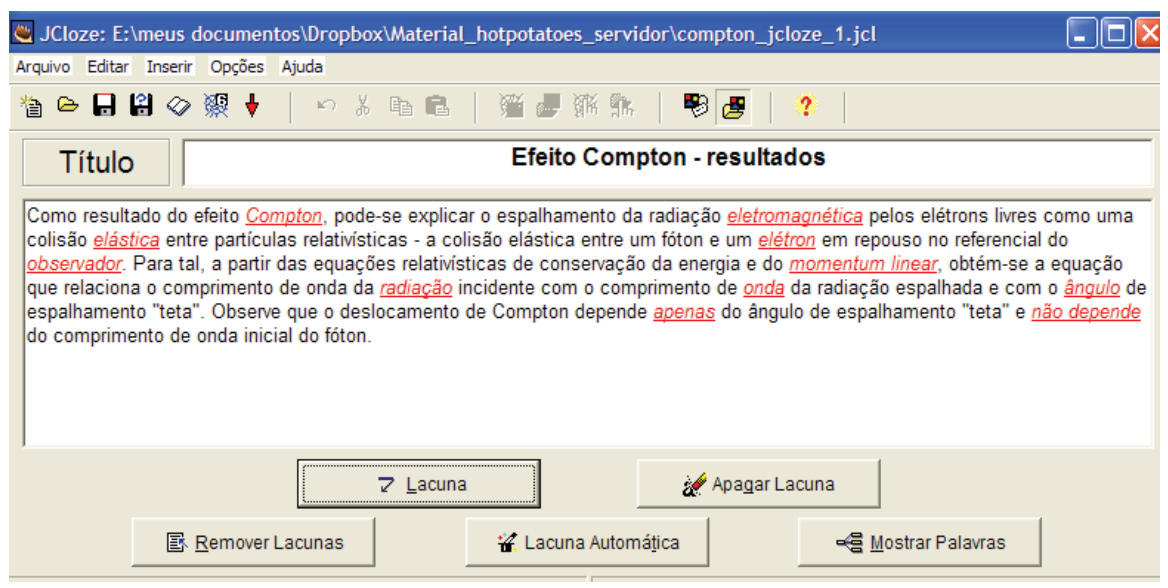

Fig. 10 - A captura de tela mostra um exercício de preencher lacunas do texto que está sendo criado com o JCloze. As palavras sublinhadas no texto correspondem às lacunas na versão final do exercício.

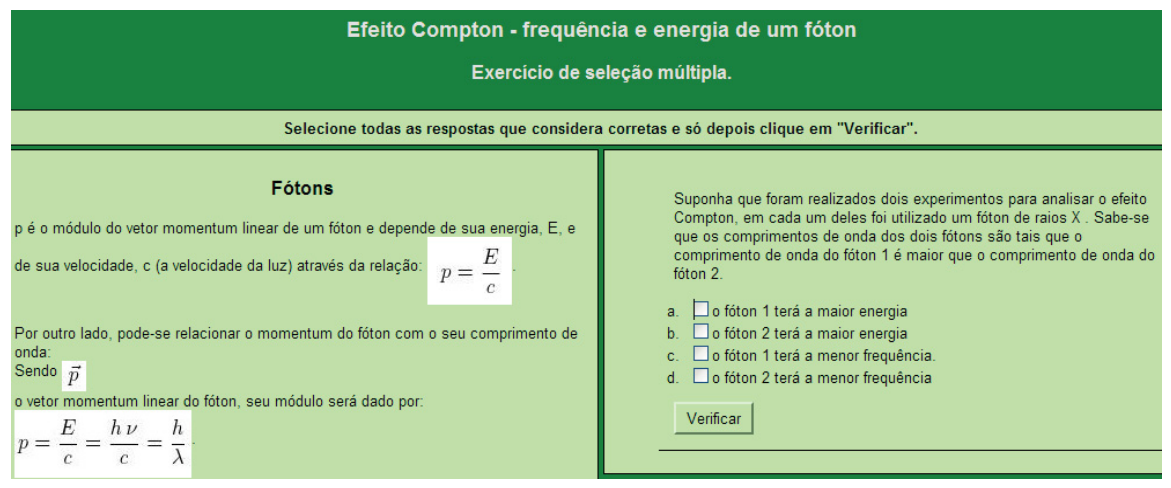

Fig. 11 - Captura de tela que mostra um teste de seleção múltipla elaborado com o JQuiz. Na parte esquerda da figura aparece o texto de apoio inserido no próprio exercício.

Talvez seja útil enfatizar que os testes eletrônicos construídos com o aplicativo HotPotatoes servem apenas para que o aluno possa verificar informalmente os seus conhecimentos, não podendo ser utilizados, por exemplo, para provas avaliativas, isso porque as respostas certas estão armazenadas, sem criptografia, no arquivo gerado, de maneira que poderiam ser descobertas facilmente por um aluno com algum talento de hacker. Além disso, não há mecanismo de armazenamento 
das respostas fornecidas pelo aluno, para posterior avaliação pelo professor. Para tais objetivos, devem-se procurar outras ferramentas.

\section{Mapas conceituais com CmapTools}

Mapas conceituais ${ }^{[38]}$ são de grande utilidade em atividades didáticas, tanto como auxílio à preparação de uma aula pelo professor, quanto como meio de verificação da assimilação de um corpo de conhecimentos pelo aluno. Evidentemente, é possível desenhar um mapa sobre uma folha de papel ou no quadro-negro, mas, além de facilitar bastante o trabalho, a informática ajuda a tornar o produto final mais atraente e rico em conteúdo. O software CmapTools ${ }^{[24]}$, apresentado no último capítulo do material, é talvez o melhor e mais conhecido recurso disponível para esse fim.

O capítulo do material dedicado a esse software começa com algumas considerações sobre mapas conceituais e uma apresentação resumida das boas estratégias para construí-los, sendo o aluno orientado a consultar outras referências, em especial o texto fundamental de Novak e Canãs ${ }^{[39]}$ e o artigo de Tavares ${ }^{[40]}$ para mais detalhes e exemplos. Como tópico ilustrativo, foi escolhida a eletrodinâmica, mais especificamente, inicia-se o estudo pelo desenvolvimento de um mapa focando a pergunta "como interagem partículas carregadas?". Recomendase, geralmente, começar com uma lista (o "estacionamento de conceitos") de termos associados ao tema da questão, e que provavelmente constituirão elementos do mapa; no caso, propõe-se a lista: carga elétrica, campo elétrico, campo magnético, força, energia, momentum linear, velocidade, propagação, retardamento.

Definido o assunto, o material ensina como inserir visualmente no mapa os conceitos e as proposições que os relacionam. São apontados vários recursos de configuração que ajudam a dar a um mapa uma aparência agradável. $\mathrm{O}$ resultado alcançado, para o primeiro mapa construído, está apresentado na Fig. 12. Uma forma diferenciada foi adotada para os retângulos que não são, propriamente falando, associados a conceitos, e sim a caracterizações de outros elementos. Nota-se, também, o uso de linhas pontilhadas para indicar relações entre elementos a priori distantes do mapa ("vínculos cruzados", na nomenclatura empregada no material).

Pode-se observar na Fig. 12 um símbolo especial (>>) associado ao conceito "força"; trata-se de um botão que permite abrir um submapa associado a esse conceito e mostrado aberto na Fig. 13. O símbolo $(<<)$ visível sobre a borda direita do submapa é um botão que permite encolher o submapa. A inclusão de tais submapas, conhecidos como nós ou nodos na documentação sobre o software, é uma das potencialidades mais notáveis de CmapTools. 


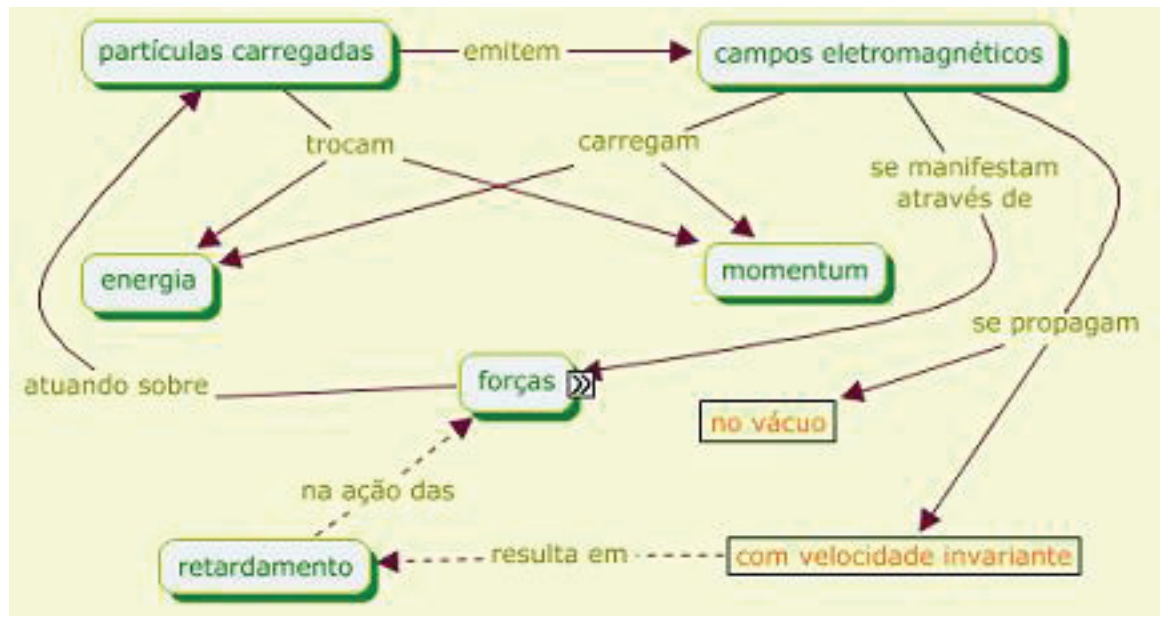

Fig. 12 - O primeiro mapa construido, após configuração dos detalhes da aparência. Ao conceito "forças" está associado um nodo, mostrado aberto na Fig. 13.

O leitor pode reparar, na Fig. 13, o uso de cores diferentes (verde e azul) para distinguir dois fluxos lógicos de proposições distintos. Essa técnica permite evitar a repetição de elementos e tornar o mapa mais compacto. Considerando que não existem convenções universais de sintaxe para os mapas conceituais, a postura aqui é de encorajar o usuário do aplicativo a usar a imaginação e experimentar várias opções.

Na verdade, não há nada na funcionalidade de CmapTools que garanta ou exija que um mapa com ele construído possa ser caracterizado como "conceitual", e ele faculta a elaboração de qualquer mapa que estabeleça relações entre elementos e associe recursos aos mesmos. A natureza dos elementos não é restrita a palavras, podendo ser, por exemplo, imagens, como no exemplo relativo a instrumentos de medidas eletromagnéticas desenvolvido no material e mostrado na Fig. 14.

O hipertexto ainda explica como associar recursos didáticos complementares, tais como textos, figuras ou links, aos elementos de um mapa. Além de uma versão modificada do mapa da Fig. 14, é usado para fins de ilustração o mapa do próprio material, já mostrado na Fig. 2. 


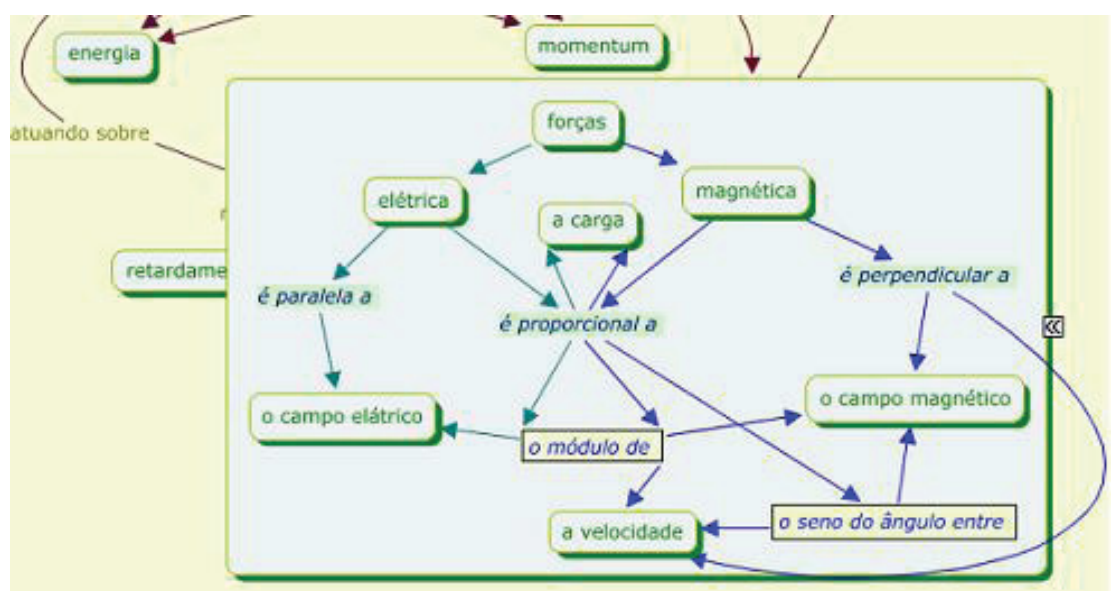

Fig. 13 - O sub-mapa aberto pelo nodo associado ao elemento "forças" da Fig. 12.

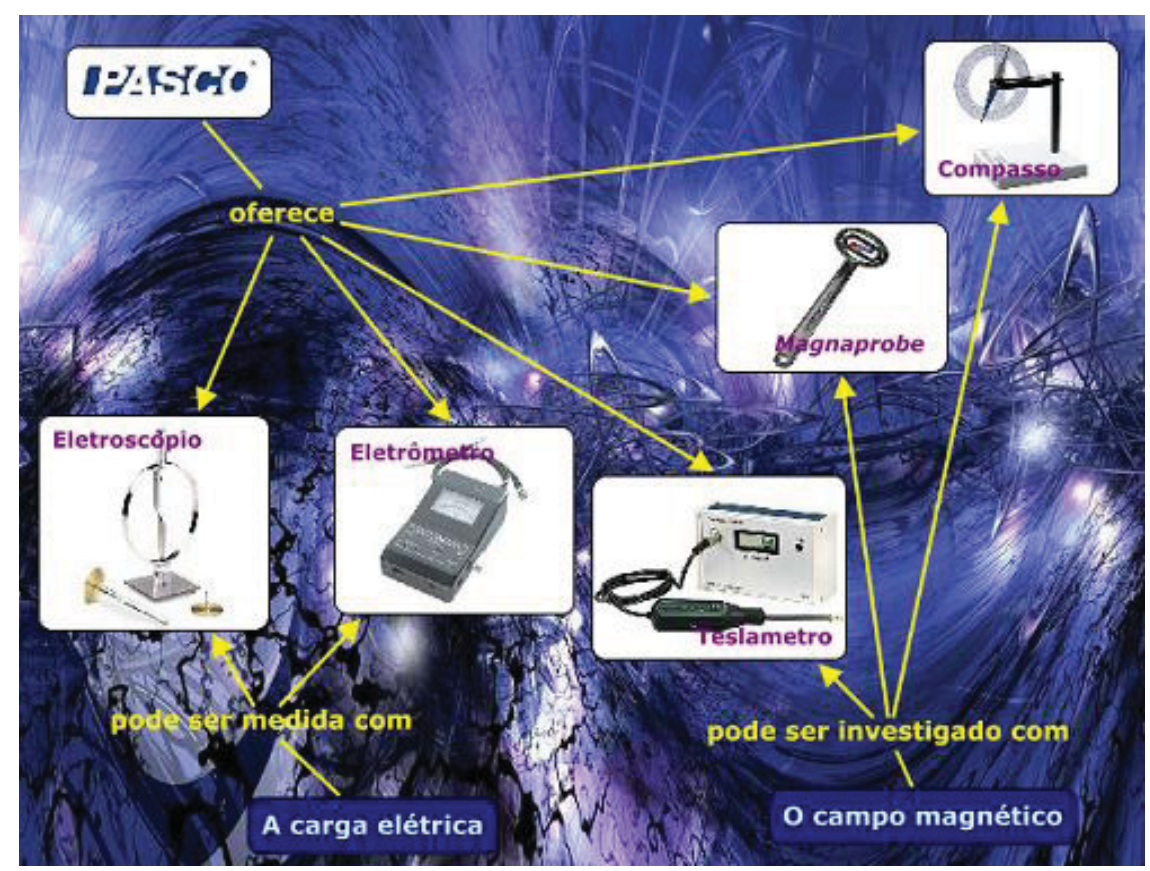

Fig. 14 - Exemplo de utilização de imagens como plano de fundo e elementos de um mapa. 
Não estão propostas tarefas específicas no fim dos Capítulos 5 e 6, mas espera-se, naturalmente, que eles sirvam de motivação para o usuário criar seus próprios mapas e testes interativos. No curso de especialização que motivou o desenvolvimento do material, o aluno era incentivado a incorporar mapas conceituais e testes interativos aos demais recursos desenvolvidos na realização do trabalho de conclusão.

\section{Utilização do material}

O material aqui relatado tem o objetivo de introduzir algumas das possibilidades de utilização dos diferentes softwares de forma a incentivar o usuário a criar os próprios materiais didáticos para uso na sua prática docente.

Ao elaborar o seu material instrucional com os softwares, sugere-se ao usuário que escolha uma de três opções de abordagem didática:

1. preparação com o software de material a ser utilizado em aula, pelo professor, como auxílio no ensino de um determinado tópico de Física;

2. preparação de material semelhante, mas a ser utilizado pelo aluno no laboratório de informática da escola;

3. elaboração de um tutorial simplificado que permita ao aluno desenvolver ele mesmo um recurso ilustrativo de algum assunto do currículo.

Nas Práticas Pedagógicas que foram realizadas pelos alunos do curso de especialização "Física para a Educação Básica", foram muito poucos os alunos que se limitaram à primeira opção e os que se aventuraram a escolher a terceira opção. A maioria preferiu combinar as duas primeiras opções, começando pela utilização de um software pelo professor em sala de aula, para depois passar a atividades dirigidas no laboratório de informática.

No que diz respeito à receptividade dos alunos aos vários aplicativos apresentados, notou-se que muitos alunos sentiam-se mais à vontade com a planilha eletrônica que com Modellus, talvez por eles terem alguma familiaridade prévia com a primeira. Embora inicialmente seduzidos pela possibilidade de construir uma animação, muitos alunos não conseguiram chegar a um resultado funcional, principalmente por não entenderem como vincular corretamente as posições e escalas dos objetos na tela às grandezas definidas e calculadas na modelagem. Os softwares HotPotatoes e CmapTools, cujas utilizações não apresentam grandes dificuldades técnicas, atraíram bastante interesse dos alunos, o que não significa, evidentemente, que todos eles conseguiram elaborar, com esses recursos, material de boa qualidade didática. 


\section{Considerações finais}

Descreve-se um material instrucional elaborado a partir de quatro softwares úteis no ensino da Física. O desenvolvimento do material didático é baseado em três componentes - o uso dos softwares, as estratégias de ensino propostas e os conteúdos de Física. Ele é organizado em capítulos, onde se recorre a um problema-exemplo de Física para descrever diferentes aspectos do software.

São dedicados dois capítulos ao estudo da planilha eletrônica, onde foi utilizado o software Calc do pacote BrOffice, embora o usuário, se preferir, poderá usar o Excel do MicrosoftOffice. Os principais recursos oferecidos pelo software Modellus são discutidos em dois outros capítulos. Para facilitar a elaboração de testes interativos eletrônicos, é apresentado o software HotPotatoes. Finalmente, um capítulo é dedicado à discussão e elaboração de mapas conceituais utilizando o software CmapTools.

Grande parte do material instrucional apresentado foi elaborada e utilizada em um Curso de Especialização para professores de Física da educação básica, oferecido na modalidade EAD, constituindo a disciplina Métodos Computacionais no Ensino da Física e tendo sido editada sua versão impressa ${ }^{[41]}$. A apresentação do material na forma de um hipertexto combinando um tutorial de uso do software com uma contextualização na Física parece ter agradado aos professores-alunos daquele curso. Esse foi um dos motivos de se pretender divulgar de forma mais ampla esse material didático, com acesso livre através de um servidor ${ }^{[25]}$.

Naturalmente, o material didático aqui descrito poderá ser útil em outros contextos. No Ensino Superior, em uma disciplina de Licenciatura em Física, ele servirá para o professor que desejar lançar mão de recursos computacionais. $\mathrm{Na}$ escola, um professor com maior motivação e aptidão no uso da informática poderá utilizá-lo, ou mesmo adaptá-lo, para promover e difundir o uso da informática educacional entre seus colegas.

Mesmo que a discussão feita aqui se restrinja a quatro softwares representativos com utilidade no ensino da Física, espera-se que o usuário, após se familiarizar com esse material, adquira autoconfiança suficiente para descobrir e utilizar outros softwares que ofereçam recursos interessantes para apoiar as suas atividades didáticas. As habilidades e as competências adquiridas irão certamente auxiliá-lo na sua prática docente, proporcionando abordagens didáticas inovadoras e contribuindo para torná-lo capaz de enfrentar os desafios atuais do ensino da Física. 


\section{Agradecimentos}

Os autores agradecem o auxílio recebido do Fundo Nacional de Desenvolvimento da Educação quando da elaboração deste material instrucional.

\section{Referências}

${ }^{[1]}$ TALIM, S. L. A atitude no ensino de física. Caderno Brasileiro de Ensino de Física, Florianópolis,v. 21, n. 3, p. 313-324, dez. 2004.

${ }^{[2]}$ RICARDO, E. C.; FREIRE, J. C. A. A concepção dos alunos sobre a física do ensino médio: um estudo exploratório. Revista Brasileira de Ensino de Física, São Paulo, v. 29, n. 2, p. 251-266, jun. 2007.

${ }^{[3]}$ BROCK, C.; DA ROCHA FILHO, J. B. Algumas origens da rejeição pela carreira profissional no magistério em física. Caderno Brasileiro de Ensino de Física, Florianópolis, v. 28, n. 2, p. 356-372, ago. 2011.

[4] PIETROCOLA, M. A matemática como estruturante do conhecimento físico. Caderno Catarinense de Ensino de Física, Florianópolis, v. 19, n. 1, p. 89-109, ago. 2002.

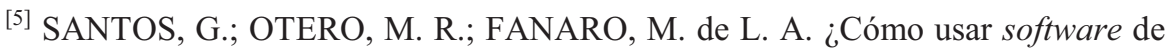
simulación en clases de Física? Caderno Brasileiro de Ensino de Física, Florianópolis, v. 17, n. 1, 50-66, abr. 2000.

${ }^{[6]}$ MEDEIROS, A.; MEDEIROS, C. F. de. Possibilidades e limitações das simulações computacionais no ensino de Física. Revista Brasileira de Ensino de Física, São Paulo, v. 24, n. 2, p. 77-86, jun. 2002.

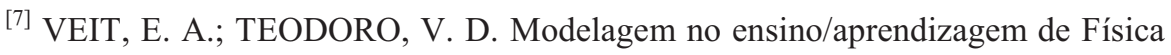
e os novos parâmetros curriculares nacionais para o Ensino Médio. Revista Brasileira de Ensino de Física, São Paulo, v. 24, n. 2, p. 87-96, jun. 2002.

${ }^{[8]}$ FIOLHAIS, C.; TRINDADE, J. Física no computador: o computador como uma ferramenta no ensino e na aprendizagem das ciências físicas. Revista Brasileira de Ensino de Física, São Paulo, v. 25, n. 3, p. 259-272, set. 2003.

${ }^{[9]}$ SENA DOS ANJOS, A. J. As novas tecnologias e o uso dos recursos telemáticos na educação científica: a simulação computacional na educação em Física. Caderno Brasileiro de Ensino de Física, Florianópolis, v. 25, n. 3, p. 569-600, dez. 2008. 
${ }^{[10]}$ PAIVA, J. C.; COSTA, L. A.; FIOLHAIS, C. "MOCHO": um portal de ciência e cultura científica. In: CONGRESSO IBEROAMERICANO DE INFORMÁTICA EDUCATIVA, VI, 2002, Vigo, Espanha. Actas... Disponível em:

$<$ http://lsm.dei.uc.pt/ribie/docfiles/txt2003729192434paper-117.pdf>. Acesso em: 27 jul. 2012.

[11] ERTMER, P. A.; OTTENBREIT-LEFTWICH, A. T.; SADIK, O.; SENDURUR, E.; SENDURUR, P. Teacher beliefs and technology integration practices: a critical relationship. Computers \& Education, v. 59, n. 2, p. 423-435, September 2012.

${ }^{[12]}$ LOWTHER, D. L.; INAN, F. A.; STRAHL, J. D.; ROSS, S. M. Does technology integration "work" when key barriers are removed? Educational Media International, v. 45, n. 3, p. 195-213, September 2008.

${ }^{[13]}$ CALC. Disponível em: <http://www.broffice.org/download>. Acesso em: 16 jan. 2012.

${ }^{[14]}$ MICROSOFT EXCEL. Disponível em:

$<$ http://www.microsoftstore.com.br/shop/pt-BR/Microsoft/Office>. Acesso em: 27 jul. 2012.

${ }^{[15]}$ MODELLUS. Disponível em: < http://modellus.fct.unl.pt/>. Acesso em: 16 jan. 2012.

[16] INTERACTIVE PHYSICS. Disponível em: <http://www.designsimulation.com/ip/index.php>. Acesso em: 27 jul. 2012.

[17] ALGODOO. Disponível em: <http://www.algodoo.com/wiki/Home>. Acesso em: 27 jul. 2012.

${ }^{[18]}$ PHET. Disponível em: <http://phet.colorado.edu/>. Acesso em: 23 jul. 2012.

${ }^{[19]}$ PHYSLETS. Disponível em:

$<$ http://webphysics.davidson.edu/Applets/Applets.html >. Acesso em: 23 jul. 2012.

${ }^{[20]}$ FENDT, W. Applets Java de Física. Disponível em: <http://www.walterfendt.de/ph14br/>. Acesso em: 23 jul. 2012.

[21] TRACKER. Disponível em: <http://www.cabrillo.edu/ dbrown/tracker/>. Acesso em: 27 jul. 2012. 
${ }^{[22]}$ HOTPOTATOES. Disponível em: <http://hotpot.uvic.ca/>. Acesso em: 16 jan. 2012.

${ }^{[23]}$ GOOGLE DOCS. Disponível em: <http://www.google.com/google-d-s/intl/ptBR/forms/>. Acesso em: 27 julho 2012.

${ }^{[24]}$ CMAPTOOLS. Disponível em: <http://cmap.ihmc.us/>. Acesso em: 16 jan. 2012.

${ }^{25]}$ Disponível em: <http://www.if.ufrgs.br/computador_ensino_fisica>. Acesso em: 16 jan. 2012.

${ }^{[26]}$ BARBOSA, A. C. C.; CARVAlHAES, C. G.; COSTA, M. V. T. A computação numérica como ferramenta para o professor de Física do Ensino Médio. Revista Brasileira de Ensino de Física, São Paulo, v. 28, n. 2, p. 249-254, jun. 2006.

${ }^{[27]}$ OLIVEIRA, M. C.; NÁPOLES, S. Using a spreadsheet to study the oscillatory movement of a mass-spring system. Spreadsheets in Education (eJSiE), Robina, v. 3, n. 3, 2010. Disponível em:

$<$ http://epublications.bond.edu.au/ejsie/vol3/iss3/2>. Acesso em: 16 jan. 2012.

${ }^{[28]}$ BLOCH, S. C. Excel para engenheiros e cientistas. 5. ed. São Paulo: LTC Editora, 2004.

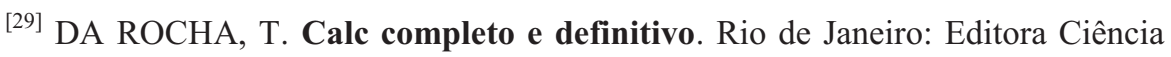
Moderna, 2006.

${ }^{[30]}$ EASY JAVA SIMULATIONS. Disponível em: <http://fem.um.es/Ejs/>. Acesso em: 27 jul. 2012.

[31] VPYTHON. Disponível em: <http://www.vpython.org/>. Acesso em: 27 jul. 2012.

${ }^{[32]}$ TEODORO, V. D. Modellus: learning physics with mathematical modelling. Disponível em: $<$ http://modellus.fct.unl.pt/mod/resource/view.php?id=334>. Acesso em: 16 jan. 2012.

${ }^{[33]}$ AGUIAR, C. E. Informática para o ensino de Física, material didático impresso do Centro de Educação Superior a Distância do Estado do Rio de Janeiro. Disponível em: <http://omnis.if.ufrj.br/ carlos/infoenci/notasdeaula/roteiros/>. Acesso em: 16 jan. 2012.

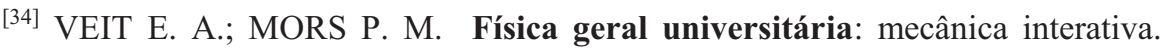
Belo Horizonte: Editora da UFMG, 2010. 
[35] AGUIAR, C. E.; RUBINI, G. A aerodinâmica da bola de futebol. Revista Brasileira de Ensino de Física, São Paulo, v. 26, n. 4, p. 297-306, 2004.

${ }^{[36]}$ DORNELES, P. F. T.; VEIT, E. A.; MOREIRA, M. A. A study about the learning of students who worked with computational modeling and simulation in the study of simple electric circuits. Revista Electrónica de Enseñanza de las Ciencias, Vigo, v. 9, n. 3, p. 569-595, 2010. Disponível em: $<$ http://www.saum.uvigo.es/reec/volumenes/volumen9/ART5_Vol9_N3.pdf>.

Acesso em: 16 jan. 2012.

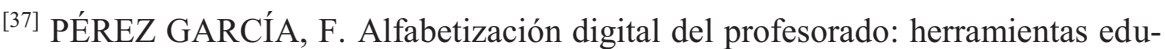
cativas interactivas. Didáctica, Innovación y Multimedia, n. 16, 2010.

${ }^{[38]}$ CAÑAS, A. J.; NOVAK, J. D. Facilitating the adoption of concept mapping using CmapTools to enhance meaningful learning. In: OKADA, A, BUCKINGHAM SHUM, S. J., SHERBORNE, T (Eds). Knowledge Cartography, Software Tools and Mapping Techniques. Springer, 2008, p. 25-46. Disponível em:

$<$ http://www.springerlink.com/content/m0wp478877731522/fulltext.pdf $>$. Acesso em: 16 jan. 2012.

${ }^{\left[{ }^{39]}\right.}$ NOVAK, J. D.; CANÃS A. J. The theory underlying concept maps and how to construct them, Technical Report IHMC CmapTools 2006-01 Rev 01-2008, Florida Institute for Human and Machine Cognition, 2008". Disponível em: $<$ http://cmap.ihmc.us/Publications/ResearchPapers/TheoryUnderlyingConceptMap s.pdf>. Acesso em: 16 jan. 2012.

[40] TAVARES, R. Construindo mapas conceituais. Ciências \& Cognição, v. 12, 72-85, 2007. Disponível em:

$<$ http://www.cienciasecognicao.org/revista/index.php/cec/article/view/641>. Acesso em: 16 jan. 2012.

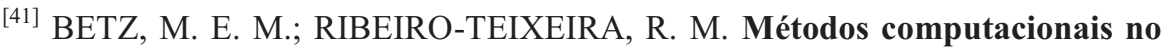
ensino de Física. Porto Alegre: Editora Evangraf; UFRGS, 2011. 174 p. 